\title{
APRESENTAÇÃO DOSSIÊ RESISTÊNCIA E DISTOPIA
}

\author{
João Luis Pereira Ourique \\ Douglas Eraldo dos Santos
}

Neste exemplar da Revista Eletrônica Literatura e Autoritarismo reunimos em formato de dossiê um relevante conjunto de artigos propondo reflexões a partir das temáticas Resistência e Distopia. Para integrar as discussões, que a despeito de suas particularidades, estabelecem diálogos interconectados, optamos por dividir o dossiê em duas partes, sendo sua primeira parte, Marcas da violência e o testemunho da resistência em que os trabalhos apresentados se propõem a diferentes análises sobre a violência e de que forma a arte, literária ou cinematográfica, acaba se confrontando com essa questão. Dessa forma, temos um conjunto de trabalhos que refletem desde a violência introjetada no indivíduo à violência perpetrada e organizada pelos projetos de poder, pois como lembra Ricouer (2011, p. 95), "É fato não existir comunidade histórica alguma que não tenha nascido de uma relação, a qual se pode chamar de original, com a guerra" tendo aqui guerra como ápice de todas as violências e exercício último em que se desdobra a barbárie. Assim, discutir a violência num país como o Brasil, onde ela "aparece como constitutiva da cultura nacional, como elemento 'fundador"” (SCHOLLHAMMER, 2000, p.236-7) é extremamente relevante, não apenas na compreensão de suas lógicas, como pela observação das perspectivas que possibilitam o enfrentamento e a resistência a este discurso, manifestadas no interior da obra de arte. Aliás, neste sentido é importante lembrar de que "resistência é um conceito originariamente ético, e não estético" e que em "seu sentido mais profundo apela para a força da vontade que resiste a outra força, exterior ao sujeito. Resistir é opor a força própria à alheia” (BOSI, 1996, p.11). Os trabalhos aqui reunidos a partir de diferentes gêneros da arte procuram compreender tais forças de resistência, uma resistência que pode ser expressa pelo sujeito que expõe seus pensamentos em um diário, quando pensar possa ser considerado "proibido", ou simplesmente resistir não submergindo a coletividade que evoca a naturalização de posturas primitivas, forças que se opõem a qualquer tipo de regressão civilizatória. É o que veremos nos trabalhos reunidos neste dossiê, a começar pelos cinco artigos iniciais que debatem o funcionamento da resistência frente às diferentes marcas da violência.

$\mathrm{O}$ primeiro artigo desta edição apresenta $\mathrm{O}$ duelo entre materialidades: a representação da violência no conto "O duelo", de Guimarães Rosa, e no filme homônimo, de Paulo Thiago, de Juliana Marschal Ramos, Lívia Stumpf e Cristiane da Silva Alves, que principia a presente publicação com a análise de um autor cujo trabalho é sólido e profundo na observação da violência enquanto constituinte social de um país marcado por esse elemento enquanto constituinte de uma cultura; nos contos de Guimarães Rosa e em seu romance basilar, Grande Sertão: Veredas a violência será uma temática recorrente. Todavia, as autoras focalizam sua análise em um trabalho específico de Rosa, o conto O duelo, publicado no li- 
vro Sagarana e na violência "praticada entre homens" e de que modo essa violência é transposta para a adaptação cinematográfica homônima revelando que "a violência que ficava relegada a ameaças no livro, passa a ser demonstrada por cenas de tiros, sangue e morte".

O segundo trabalho aqui reunido, A resistência ao discurso nacionalista hegemônico na dramaturgia de Sean O’Casey, de Raimundo Expedito dos Santos Sousa, por sua vez, perscruta a relação entre violência e projetos políticos de poder, como o nacionalismo, no estudo específico o nacionalismo irlandês que "a fim de provar a virilidade dos homens irlandeses, subestimados pelo império britânico, o nacionalismo anticolonial implicou suspensão provisória do código de masculinidade civil em favor do código de masculinidade cívica”. Em sua argumentação, a partir da análise da dramaturgia de Sean O'Casey, o autor defende que "o projeto de nação irlandês instaurou um código de hipermasculinidade que demandava, em complemento, um código de hiperfeminilidade análogo", uma demanda provocadora - e estimuladora - de diferentes violências.

$\mathrm{Na}$ sequência das discussões, Testemunha dentro e fora: violência, trauma e memória em Martyrs (2008), de Silas Rodrigues Machado, Antonio Rediver Guizzo e Fernando Mesquita de Faria aborda "a relação entre o prazer e o horror do espectador diante da representação imaginária da violência a partir da análise do filme franco-canadense Martyrs (2008)". No artigo os autores mostram que é "possível observar que atualmente temos novas escritas de imagens de violência capazes de suscitar questões relacionadas às barbaridades dos conflitos no mundo contemporâneo" e que "Martyrs (2008) não é apenas um filme que banaliza a violência, mas sim, um resgate crítico do trajeto do consumo de imagens de violência, seja ligado ou desligado da arte, contribuindo para a reformulação da escrita de violência no cinema".

Já em O "tourbillon" social: a representação da cidade moderna na poesia de Allen Ginsberg e Roberto Piva, os autores Patrícia Lochini e Paulo Andrade, por meio de um estudo comparativo, têm como objetivo mostrar "como a poesia da segunda metade do século XX encena o sentimento de revolta, romântico por excelência, à cidade como ambiente de alienação, partindo dos modernistas da década de 50" através da literatura do poeta "beatnik" norte-americano Allen Ginsberg e do poeta brasileiro Roberto Piva, especialmente suas visões acerca "da cidade" enquanto espaço de desventuras e de violência, ao que em suas conclusões acerca do trabalho do poeta brasileiro e sua análise desta metrópole, no caso representada pela cidade de São Paulo, é percebida "nas suas características subdesenvolvidas, que fazem-a parecer arruinada, envelhecida, que irradia uma delicadeza singular. E nos traços de humanidade que ainda sobrevivem nestes escombros nasce uma outra esperança de preencher o vazio existencial que perturba nossa humanidade".

Encerrando a primeira parte deste dossiê, Notas para uma poética da resistência, de Raul Azevedo de Andrade Ferreira, "realiza uma reflexão sobre como a noção de resistência pode ser pensada a partir do discurso poético". Tudo isto posto na perspectiva do aumento da tensão autoritária recente, tendo como realidade social, por exemplo, o avanço da extrema-direita no Brasil e dos impactos deste discurso radical e excludente. Para tanto, em sua análise o autor analisa a poética marginal de Miró da Muribeca propondo que "a poesia de Miró parte sobretudo das experiências daqueles que mais sofrem as contradições e injustiças da vida urbana". 
Em sua segunda parte, Distopias, este dossiê completa-se reunindo outros cinco artigos, unidos pelo elemento comum das narrativas distópicas. A este momento é importante frisar que a opção pela edição deste exemplar em duas partes se dá em razão do elemento unificador dos trabalhos de sua segunda parte e não por alguma distinção drástica entre as temáticas. Pelo contrário, pensamos que ambas possibilitam a construção de diálogos, pois que as distopias enquanto ferramentas de crítica social são marcadas pelas reflexões acerca tanto da violência, suas marcas, seus traumas, como também pela resistência, como "as pequenas vitórias sobre a memória”, evocadas pelo protagonista Winston Smith, de 1984. Nesse sentido, tal divisão é um convite aos leitores para a construção de pontes entre as respectivas partes desta edição lembrando que enquanto gênero, as distopias vêm sendo discutidas com certa força recentemente. Em parte, talvez em virtude do assombro e espanto perante retrocessos sociais e a escalada da ideologia autoritária pelo mundo, especialmente a partir da segunda década deste século. Na literatura e no cinema algumas narrativas pretensamente classificadas como distopias, caso de Jogos Vorazes (2008), por exemplo, obtiveram muito interesse popular, assim como adaptações para a televisão de livros como O Conto da Aia, de Margaret Atwood (1985), obra discutida em dois artigos desta edição. Todavia, vale ressaltar que grande parte destas publicações recentes acaba tendo certa distância das narrativas originais, tanto que Adam Roberts em sua A Verdadeira História da Ficção Científica (2018) acaba chamando estas publicações de "brandas distopias", embora o próprio crítico-teórico reforce que esse sequer seja o melhor termo para tal. Faz sentido a crítica quando pensamos as distopias como a imagem de um pesadelo do qual não conseguimos acordar. Nelas o sofrimento é permanente. Tanto que o termo "pesadelo orwelliano" é bastante corriqueiro para descrever situações de opressão, violência e autoritarismo. O pesadelo é, portanto, um dos principais signos do gênero distópico, nascido dos dramas humanos em finais de século XIX e especialmente no século XX, quando narrativas significativas como Nós (1925), Admirável Mundo Novo (1932) 1984 (1949), Fahrenheit 451 (1953), entre outras, foram publicadas, formando um quarteto básico de referências e influências para outras obras no gênero. Vale reforçar que as distopias surgem a partir da incapacidade do pensamento utópico em dar conta dos novos dramas sociais da era moderna, e também da reflexão acerca das estruturas autoritárias presentes no utopismo. Conforme Booker (1994, p.3) a "literatura distópica é especificamente a literatura que se posiciona em direção oposta ao pensamento utópico, alertando contra as potenciais consequências negativas do utopismo". Nesse sentido "a negatividade, característica marcante das distopias, em geral, funciona como uma forma de se expressar uma visão das assimetrias e desigualdades encontradas no mundo contemporâneo" (QUEIROGA E LIEB, 2008, p.312). As distopias enquanto oposição ou negativa das utopias e enquanto narrativas de crítica social conduzirão os artigos da segunda parte desta edição, assim como, o potencial de alerta e de denúncia do gênero dos mecanismos de controle, violência e opressão.

O primeiro artigo desta parte é The Anti-Authoritarian Role Of Dystopias: Reflections On Érico Veríssimo's Novel Incident In Antares, de Fabiana Maria Baptist e Guilherme Prado Roitberg. Os autores relacionam o realismo mágico de Incidente de Antares às narrativas distópicas enquanto contraposição ao pensamento utópico e enquanto crítica ao autoritarismo presente em seu contexto social e histórico. No presente trabalho eles investigam 
"de que maneira Veríssimo denunciou através de sua sociedade distópica as mais profundas contradições de um país historicamente assolado por golpes de Estado e ditaduras militares". Mais do que isso, o texto ainda defende a prevalência desta crítica, visto que muitos dos mecanismos criticados na distópica Antares, como formas de repressão e violência permanecem presentes na sociedade brasileira.

Já o segundo trabalho Corporatopia e caostopia: os espaços distópicos na trilogia MaddAddam, de Margaret Atwood, da da autoria de Pedro Fortunato e Ildney Cavalcanti, apresenta "uma análise dos espaços distópicos na trilogia MaddAddam (2003, 2009, 2013), da escritora canadense Margaret Atwood". Partindo dos estudos acerca das distopias e tendo como recorte a passagem pré-apocalíptica dos romances analisados, os pesquisadores por meio de uma dupla de amálgamas discute duas visões de sociedade, marcadas pelo pesadelo de extremo terror e opressão. Corporatopia serve-lhes como análise de perfil das sociedades distópicas tendo como agentes controladores da violência e da opressão as corporações privadas. O artigo salienta que nesses modelos tais violências são "maquiadas" pela promessa utópica de segurança, enquanto Caostopia revela sociedades marcadas pelos caos e pela ineficiência e inação do Estado. Em sua análise, os pesquisadores observam na obra de Atwood a "tendência capitalista de empoderar as corporações ao ponto de influenciar e até controlar os governos que passam a governar para as próprias corporações em detrimento dos interesses da maior parte da população".

Já o terceiro artigo desta edição, Literatura Distópica, ontem e hoje: um percurso na História e na Ficção, de Valéria da Silva Medeiros e Andrea Martins Lameirão Mateus, realiza uma reflexão sobre o percurso histórico das narrativas distópicas e a relação destas narrativas com o presente contemporâneo. Perpassando pela leitura de diferentes narrativas distópicas, do pesadelo orwelliano em 1984 ao mais recente The Handmand Tales, de Margaret Atwood. Os autores apontam para questões como o possível fracasso de uma sociedade baseada num projeto iluminista, de modo que "uma possível leitura do interesse renovado pela distopia como radicalização da razão criadora/destruidora do homem, expondo a impossibilidade da racionalidade técnica se impor sobre a irracionalidade humana".

Na sequência, Um presente para o futuro: a distopia contemporânea e suas interseções com a experiência pós-moderna, de Millena Cristina Silva Portela e Maria Aracy Bonfim Serra Pinto, "tem como objetivo o estudo da literatura distópica contemporânea como um dos gêneros que privilegiam a experiência pós-moderna através de sua crítica e reflexão das problemáticas deste conturbado tempo" sendo que as autoras refletem que "a distopia não é a única possibilidade complexa que pode ser encontrada na literatura contemporânea, mas, talvez, seja a que mais contempla as problemáticas e a experiência do sujeito pós-moderno, pois explora diversos vetores do seu universo".

Encerrando esta segunda parte e consequentemente este dossiê, A estrada: canibalismo e experiência moral, de Ícaro Yure Freire de Andrade, "tem como finalidade analisar a relação entre a indústria cultural, a produção e reprodução de valores" procurando compreender "as dimensões morais e ideológicas atribuídas às imagens do canibalismo no filme A Estrada (2009)" de modo que o "exagero adotado pela ideia do canibalismo adquire um caráter de 'fantasmagoria', isto é, a tentativa de resolver um dilema moral que nasce da própria experiência contemporânea". 
Apresentados os respectivos trabalhos deste dossiê, gostaríamos de agradecer aos pesquisadores que dedicaram tempo e trabalho cujo resultado é um documento coeso em seu todo, analisando sob diferentes perspectivas os impactos da violência no cotidiano social, mas, para além disso, como os sujeitos - expressos nas artes aqui estudadas - comportam-se nestes distintos cenários e sob distintas manifestações, entre a resistência política à opressão perpetrada por atos de violência, bem como ela, em alguns casos, naturaliza-se de tal modo a ser elemento constituinte de nações, seja expressa em coletivos ou na individualidade de sujeitos que persistem em se impor pela força da violência e de toda a carga histórica que ela tem percorrido no caminhar da humanidade.

\section{BIBLIOGRAFIA}

BOOKER, M. Keith. Dystopian literature: a theory and research guide. Westport: Greenwood, 1994.

BOSI, Alfredo. Narrativa e resistência, in Revista Itinerários. Araraquara, SP, 1996. 11-27pp.

QUEIROGA, Marcílio Garcia de; LIEBIG, Sueli Meira. Estudos Literários em Perspectiva: João Pessoa, 2008.

RICOEUR, Paul. A memória, a história, o esquecimento. Campinas, SP: Unicamp, 2011.

ROBERTS, Adam. A verdadeira história da ficção científica. Seoman: São Paulo, 2018.

SCHOLLHAMER, Karl Erik. Os cenários urbanos da violência na literatura brasileira. In: PEREIRA, Carlos Alberto Messeder [et al.].(org). Linguagens da violência. Rocco: Rio de Janeiro, 2000. 
